\title{
Swell and Wind-Sea Distributions over the Mid-Latitude and Tropical North Atlantic for the Period 2002-2008
}

\author{
Eduardo G. G. de Farias, ${ }^{1}$ João A. Lorenzzetti, ${ }^{1}$ and Bertrand Chapron ${ }^{2}$ \\ ${ }^{1}$ Divisão de Sensoriamento Remoto, Instituto Nacional de Pesquisas Espaciais (INPE), \\ CP 515 12227-010 São José dos Campos SP, Brazil \\ ${ }^{2}$ Laboratoire d'Océanographie Spatiale, Institut Français de Recherche pour l'Exploitation de la Mer (IFREMER), \\ 7029280 Plouzané, France \\ Correspondence should be addressed to Eduardo G. G. de Farias, gentil@dsr.inpe.br
}

Received 29 November 2011; Revised 28 December 2011; Accepted 19 January 2012

Academic Editor: Swadhin Behera

Copyright (C) 2012 Eduardo G. G. de Farias et al. This is an open access article distributed under the Creative Commons Attribution License, which permits unrestricted use, distribution, and reproduction in any medium, provided the original work is properly cited.

\begin{abstract}
We present an analysis of wind-sea and swell fields for mid-latitude and tropical Atlantic for the period 2002-2008 using a combination of satellite data (altimeter significant wave height and scatterometer surface winds) and model results (spectrum peak wave period and propagation direction). Results show a dominance of swell over wind-sea regimes throughout the year. A small but clear decrease in swell energy and an associated increase in wind-sea potential growth were observed in the NE trade winds zone. A seasonal summertime increase in wind-sea energy in the Amazon River mouth and adjacent shelf region and in African coast was apparent in the results, probably associated to a strengthening of the alongshore trade winds in these regions. Albeit with a significantly smaller energy contribution of wind-seas as compared to swell energy, we could say that a kind of mixed seas is more evident in the trade winds region, with the remaining area being highly dominated by swell energy. An analysis of wave-age shows the absence of young-seas. Only $\sim 2 \%$ of all data points was classified as wind-sea, a classification confirmed by a fit to a theoretical relation between wind speed, peak period, and significant wave height for fully developed wind-seas.
\end{abstract}

\section{Introduction}

Information on wave conditions is critical for human activities at sea. Among other activities, shipping, fishing, offshore industry, naval operations, coastal management and protection, can be adversely affected by wave conditions [1]. Government officials need timely wave information and forecasting results for decision-making. These information are necessary in the preparedness for and mitigation of ocean disasters, as well as sea-going rescue activities. Wave information may also be important in the calculations of ocean-atmosphere exchange of heat and momentum. It is now well established that the drag coefficient $C_{D}$, needed for calculating the wind stress and momentum fluxes, is dependent on wave height or wave age [2]. At very high winds and waves, $C_{D}$ may be smaller than conventionally calculated due to formation of foam layers caused by steep wave breaking water that is sheared by the strong winds
[3-5]. These results indicate that wave information should be taken into account in atmospheric modeling, particularly for cases of very strong weather systems.

Perhaps the most used lowest order classification of wave regimes is that one which separates the wave field into either, wind-sea or swell. The first regime is associated to a growing or equilibrium wave spectrum where peak period waves have phase velocity lower than the wind speed. As the wave energy grows and peak period increases, a point is reached when peak waves have phase speeds larger than the wind and will propagate out of the generation region as swell [1]. Wind-sea, as expected, should be highly correlated to the local winds. Swell fields, when generated by intense storms, can propagate out of their generation zones and travel very long distances across the ocean basins [6]. Therefore, very low correlation to the local winds should be expected for these longer waves. Sometimes a frequency of 10 seconds is used as a crude method to separate wind-sea from swell [7]. 
In a specific oceanic region, both wave regimes can and do coexist, but a predominance of one or the other regime is normally found. A mixture of swell and windsea states is normally present in the wave spectrum most of the time, making the quantification of the fraction of wind-seas and swell for large oceanic areas, or for the global ocean, a nontrivial task [8]. In coastal regions, gulfs, and bays, although mixed-seas fields are frequently observed, there is a predominance of wind-seas regime [9]. In open and large oceanic regions (as in the present study), usually there is a predominance of swell fields, which can have been generated by remote strong storms. Wind-seas, although a minor component in open oceans, are, however, always present [10]. A proper estimation of the wind-sea is needed for improving our theoretical understanding of wave growth and for validating wave models $[11,12]$. Swell waves, due to their very low dissipation rate and very long distance propagation, in a similar fashion as tsunami waves, can be a potential risk for people's safety and near shore structures, and may cause sensible beach erosion $[1,13]$.

Different methodologies and data sets have been used to characterize swell/wind-sea regimes for the global ocean or for specific ocean basins. Some studies have used wave model results $[14,15]$. Other investigations make use of satellite data, such as altimeter derived significant wave height $\left(H_{s}\right)$ or Synthetic Aperture Radar (SAR) wavenumber spectra $[6,10,16]$. All these investigations show a high incidence of swell fields over the global ocean, but more enclosed ocean basins such as the Gulf of Mexico present a dominance of wind-seas [16].

In the present work we analyze the swell/wind-sea presence in the tropical/mid-latitude North Atlantic for the period 2002-2008. We compare the results obtained by the wave energy methodology presented by [10] which uses quasi simultaneous altimeter significant wave height $\left(H_{s}\right)$ and scatterometer winds $\left(U_{10}\right)$ to an analysis of wave fields taking into account the wave age and orientation of wind in relation to the phase propagation vector [12]. The second method was applied using a blend of satellite winds and wave modeling results. The main goal of this paper is to verify the consistency of the results of these two different methods, as well as to contribute to a better understanding of the climatology of swell and wind-seas present in this region.

\section{Data and Methods}

An important component of this study is a joint use of satellite and wave model data. The use of collocated data from independent sources has been made by different authors to study swell/wind-sea climatology $[10,16]$. In principle, one could use simultaneous altimeter derived significant wave height $\left(H_{s}\right)$ and surface wind $(U)$. However, there is enough evidence about the effect of swell, which is uncorrelated with local wind, over the altimeter derived winds [17]. For the present paper, the wind data comes from scatterometer sensor, whose Bragg backscattering mechanism associated to larger incidence angles than altimeter is less sensitive to long wave effect.
For the processing, we used altimeter data (significant wave height) available in the AVISO website (http://www. aviso.oceanobs.com/) and QuikSCAT data available in Remote Sensing Systems website (http://www.ssmi.com/), for the period 2002-2008. The data set used has monthly temporal resolution and the following spatial resolution: $0.5^{\circ}$-QuikSCAT and $2^{\circ}$-Altimeter blending.

The regular QuikSCAT product consists of wind vectors (wind speed and direction) at a $25 \mathrm{~km}$ resolution across an $1800 \mathrm{~km}$ swath. The scatterometer wind vectors were derived from the radar backscatter using a semiempirical models and an inversion/ambiguity removal algorithm. The statistical interpolation used to obtain the scatterometer product is a minimum variance method related to the Kriging technique widely used in geophysical studies [18].

The altimeter product used in this work was derived using data from different satellite missions to obtain the blended altimeter product. The regular grid sampling on a global scale that allows the analysis of the climatology waves was also derived by Kriging interpolation. The following radar altimeter data were used for the generation of blended product: Topex/Poseidon, ERS-2, GFO, Jason-1, Envisat, and Jason-2 (details are available in the AVISO website http://www.aviso.oceanobs.com/).

We also used data from Wave Watch-III numerical modeling [19]. The wave model was forced with surface winds provided by ECMWF [20]. The wave fields used are provided every 3 hours at a spatial resolution of $0.5^{\circ}$ latitude $\times$ $0.5^{\circ}$ longitude. The products were generated for the period from $01 / 01 / 2002$ to $31 / 12 / 2008$. From a global grid of $1^{\circ} \times$ $1^{\circ}$ resolution, a regional nested grid with a resolution of $0.5^{\circ} \times 0.5^{\circ}$ was used for our study region. From the regional wave model output, we used peak period $\left(T_{p}\right)$ and wave propagation direction data.

All databases (satellite and model) were averaged to monthly means and were interpolated to a common $2^{\circ} \times 2^{\circ}$ lat/long grid. The final grid comprises the longitudes $10^{\circ} \mathrm{E}$ to $60^{\circ} \mathrm{W}$ and latitudes $10^{\circ} \mathrm{S}$ to $50^{\circ} \mathrm{N}$, our study region.

2.1. The Wave Energy Statistical Method (WES). One of the first studies presenting global statistical indices of windsea and swell using only satellite data is attributed to [10]. According to that study, the degree of swell and wind-sea energy can be estimated using only satellite data: altimeter $H_{s}$ and scatterometer wind $\left(U_{10}\right)$. Total wave energy $E_{0}$ can be estimated from altimeter-derived $H_{s}$ using the well known relation $H_{s}=4 E_{0}^{1 / 2}$. Wind-wave energy partition is estimated from a product of a probability of wind-sea $\left(P_{w}\right)$ and the predicted wind-sea energy $E_{p}$, given by $E_{p}=H_{p}^{2} / 16 . H_{p}$ is the predicted significant wave height $\left(H_{p}\right)$ derived from the fully developed spectrum [10] using a given wind forcing. The fraction of the swell energy $\left(E_{s}\right)$, to total energy, or the swell index (S) is estimated from

$$
\mathrm{S}=\frac{E_{s}}{E_{o}}=1-\left[\frac{H_{p}\left(U_{10}\right)}{H_{s}}\right]^{2} P_{w} .
$$


Assuming the drag coefficient is a function of wind speed as given by [21], the predicted Hp for fully developed sea can be calculated as

$$
\begin{aligned}
& H_{p}=1.614 \times 10^{-2} U_{10}^{2} \quad\left(0 \leq U_{10} \leq 7.5 \mathrm{~ms}^{-1}\right) \\
& H_{p}=10^{-2} U_{10}^{2}+8.134 \times 10^{-4} U_{10}^{3} \quad\left(7.5 \leq U_{10} \leq 50 \mathrm{~ms}^{-1}\right),
\end{aligned}
$$

where $U_{10}\left(\mathrm{~ms}^{-1}\right)$ is the $10 \mathrm{~m}$ height, neutral stratification scatterometer wind speed. If $N_{w}$ and $N_{s}$ are, respectively, the number of wind-sea and swell events, the probability of wind-seas, $P_{w}$, and swell events, $P_{s}$, can be estimated by

$$
\begin{aligned}
& P_{w}=\frac{N_{w}}{N}, \\
& P_{s}=\frac{N_{s}}{N},
\end{aligned}
$$

where $N=N_{w}+N_{s}$. Since $N=N_{s}+N_{w}, P_{s}+P_{w}=1$. The $N_{s}$ and $N_{w}$ are calculated by comparing $H_{p}$ against $H_{s}$. Points where $H_{s}>H_{p}$ are considered swell and those for $H_{s}<H_{p}$ are taken as wind-sea. Similarly, it is possible to define a Wind Sea Index (W), which is interpreted as a growing potential for wind waves, given by

$$
W=\frac{E_{p}-E_{w}}{E_{p}}=1.0-\left[\frac{H_{s}}{H_{p}\left(U_{10}\right)}\right]^{2} P_{w} .
$$

$E_{w}$, the energy of the wind-sea component, can be estimated as $E_{o} \times P_{w}$ for the wind-sea cases. For a purely swell regime, $U_{10}=0$ and $H_{s}>0$, and $S=1$. For a purely and beginning case of wind sea, $U_{10}>0$ and $H_{s}=0$ and $\mathrm{W}=1$. For a fully developed wind-sea and no swell, for a given $U_{10}, H_{s}$ follows (2), and $\mathrm{S}=\mathrm{W}=0$.

2.2. The Wave Age and Wind/Wave Direction Correlation Method (WAWD). Normally it is assumed that the mean wave propagation direction does not differ significantly from the wind direction [12]. This is a reasonable statement when there is a dominance of wind-sea. However, most of the time, waves are not strictly locally generated $[1,8]$. For a wind-sea condition, the direction of wave propagation is expected not to exceed a $90^{\circ}$ cone centered in the wind direction, that is, $45^{\circ}$ at each side to the prevailing wind direction [12]. If wave propagation direction is out of this "cone of influence," we can assume the wave field has not been generated by local winds, a situation indicative of swell.

The separation of the wind-sea and swell fields, however, does not depend solely on the wind direction propagation of waves in relation to the wind. Even if waves are propagating inside the "cone of influence," it is necessary to consider the wave age, that is, the ratio of speed of waves at the peak of spectrum $\left(C_{p}\right)$ to surface wind speed. The wave field should be considered wind-sea only if the wave propagation direction is within the "cone of influence" and the following relationship is satisfied [12]:

$$
U_{10} \cos \theta_{d}>0.83 C_{p} \text {, }
$$

where

$$
C_{p}=\frac{\omega}{k}
$$

$\omega$ is the peak angular frequency $\left(\omega=2 \pi / T_{p}\right), k$ is the peak wave number $\left(k=\omega^{2} / g\right), \theta_{d}$ is the angle between wind and wave direction, and $U_{10}$ is the local surface wind speed, in our case derived from scatterometer. Equation (5) states that the wave age (WA) for wind-seas, calculated using the wind projection in the direction of wave propagation, should be less than 1.2 [8]. $C_{p}$ was estimated using peak period $T_{p}$ generated from Wave Watch 3 model run forced with ECMWF reanalysis winds which also provided wave propagation direction [19].

\section{Results and Discussion}

Figure 1 shows the spatial distribution of the seasonal average values of swell and wind-sea indices (S and $\mathrm{W}$ ) in color and mean surface wind field (QuikSCAT) for the period 20022008. The magnitudes of $S$ and $W$ are indicated by the color bars to the right of the figures.

As indicated by other studies, which used different methodologies or distinct periods $[10,14]$, our results also support the view that for winter and summer periods swell energy highly dominates the whole region $(S>0.9)$. Our results show two swell pools $(S=1)$ in the North Atlantic: one smaller and closer to the equator near the African coast, and a larger one encompassing all midlatitudes. Results obtained by [10] show a monotonic decrease of swell index, starting from the African coast to the interior of the region (see their Figures 4(b), 4(d)). Our results show the African swell pool aligned to the surface wind convergence zone associated with the ITCZ followed by a decreasing of S index (and an associated increase of $\mathrm{W}$ index) in the $\mathrm{NE}$ trade winds region, and a northward increase again of $\mathrm{S}$ towards the North Atlantic high pressure center region. The influence of the ITCZ over the wave climate in the western tropical Atlantic is also reported by [22].

The seasonal mean wind-sea index plots show low windsea potential growth (small values of W) throughout the region, indicating the lack of wind-sea recently generated. An exception to this pattern is seen, however, as a longitudinal and northward inclined band of higher $\mathrm{W}$ values centered between $10-15^{\circ} \mathrm{N}$ in the western tropical Atlantic and 15$32^{\circ} \mathrm{N}$ near Africa and during the summer season (JJA) over the NE Brazilian/Amazon river shelf region (around $40^{\circ} \mathrm{W}$ and $0^{\circ}$ ). This band of higher $\mathrm{W}$ values is stronger in the summer period, showing also a maximum near the African coast. The increase of $\mathrm{W}$ near Brazilian coast (near the African coast) in the summer period is likely related to the strengthening of the SE (NE) alongshore trade winds in these areas which is visible in QuikSCAT winds. This seasonal strengthening of regional winds during the JJA period is documented, among others, by $[14,15]$ based in a climatology of model results (ERA-40) for the period 19582001.

Our spatial pattern of two swell pools separated by a region of higher (lower) wind-sea (swell) index is also similar 

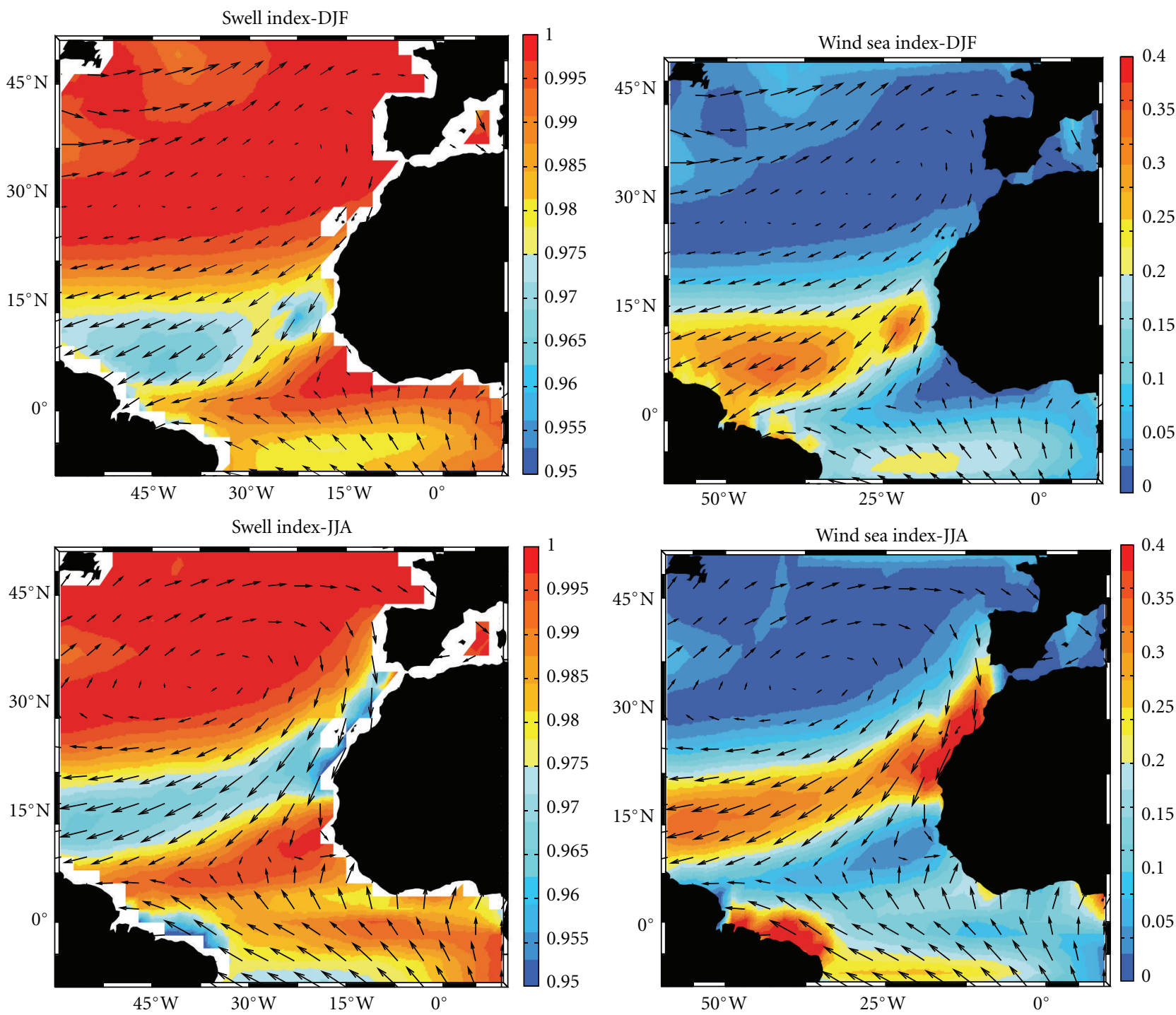

(a)

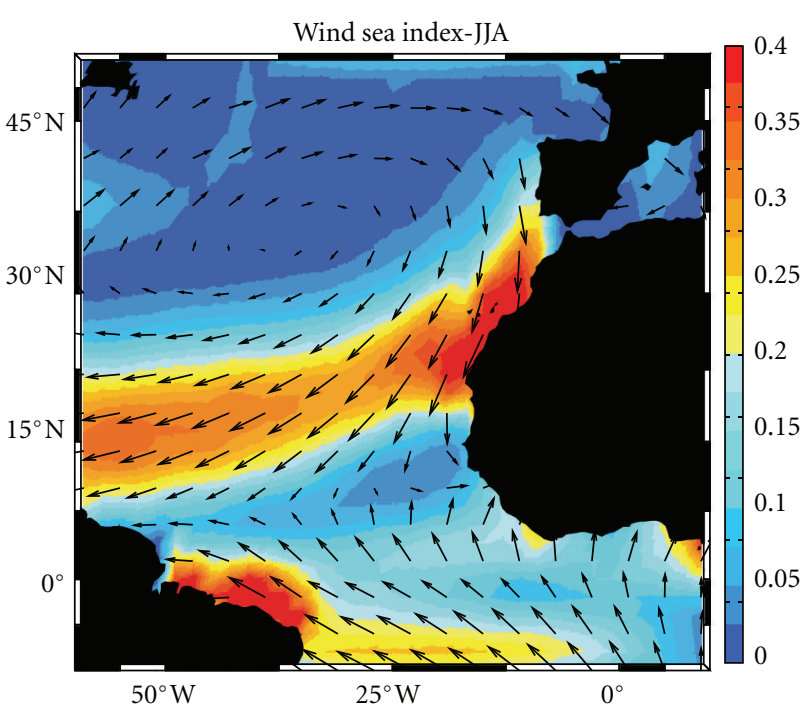

(b)

Figure 1: Mean seasonal swell (S) and wind-sea (W) indices (left and right, resp.) for NH winter (DJF) and summer (JJA) seasons for the period from 2002 to 2008. The black arrows: mean QuikSCAT winds for the same period.

to the inverse wave age plots given by [15], which were derived from wind and wave data from ERA-40 simulations (see their Figure 7). Also using ERA-40 data, [14] shows for our study region a double swell pool separated by a tongue of lower swell regime calculating a ratio of swell energy to total wave energy and by calculating a swell probability using a wave age $\left(c_{p} / U_{10}\right)$ threshold of 1.2 (their Figures 4 and 6 ). In the global distribution figures of mean monthly values of peak wave period and mean wave period of [23], it is possible to see for our study region a similar two-center cell of longer period waves separated by a longitudinal band of lower period waves (see their Figures 1(c) and 1(d) for January and July).

A characterization of wave regimes by means of wave age (WA), calculated using friction velocity $\left(u_{\text {star }}\right)$ instead of
$U_{10}$, is also frequently adopted [8]. The WA is in this case calculated by

$$
\mathrm{WA}=\frac{C_{P}}{u_{\text {star }}},
$$

where the friction velocity is given by $u_{\text {star }}{ }^{2}=C_{D} U_{10}^{2}$. $C_{D}$ is the drag coefficient, which can be calculated by $C_{D}=(0.8+$ $\left.0.065 \times U_{10}\right) 10^{-3}[8]$. Using WA, the wind-wave regime is normally separated in two categories: (a) young wind-sea, which corresponds to a high frequency peak spectrum and waves that have just been generated by the wind, and (b) old wind-seas which are associated with a saturated spectrum and are normally encountered where weak winds blow over fast propagating swell or if a local sea is slowly decaying as a storm moves out of the region [24]. If WA, as given by (7), 


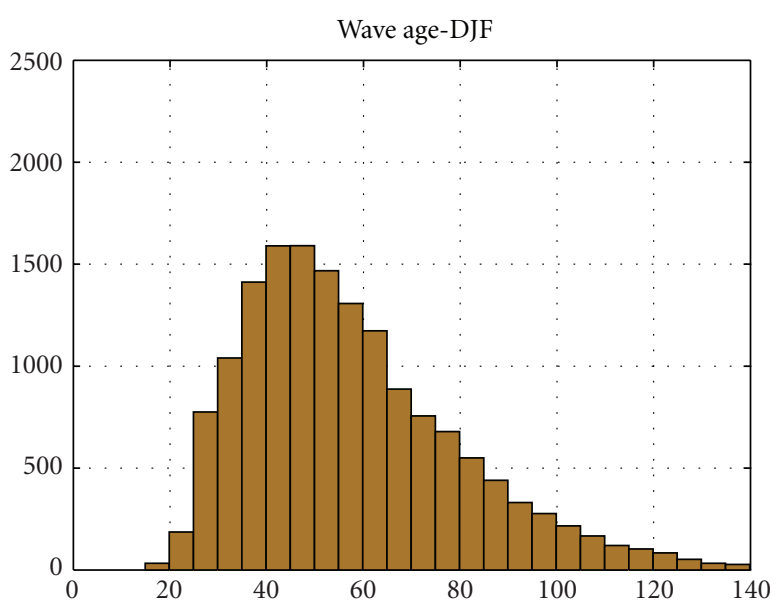

(a)

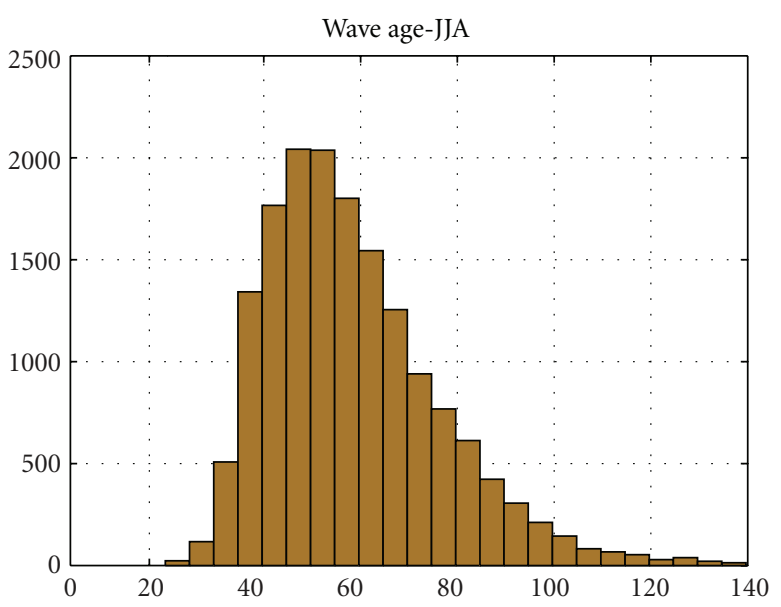

(b)

FIgURE 2: Histograms of wave age (7) for the study region. DJF: December, January, and February. JJA: June, July, and August.

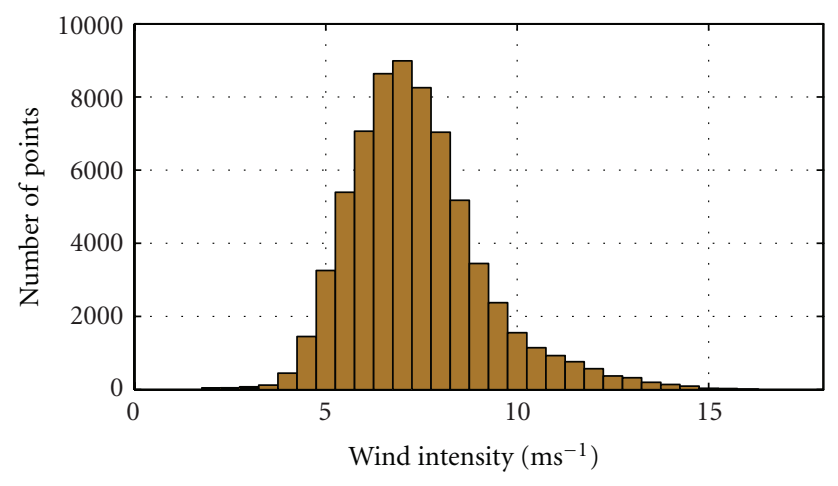

(a)

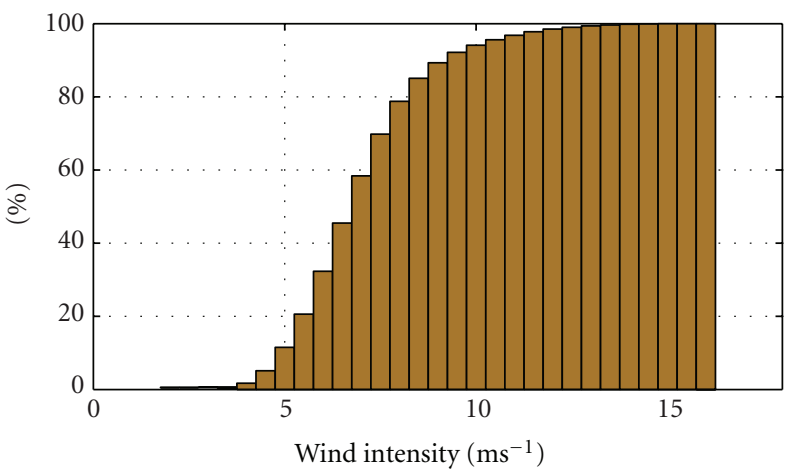

(b)

FIGURE 3: (a) Histogram of QuikSCAT wind intensity for the study region. (b) Cumulative histogram derived from QuikSCAT for our study region.

is in the range $5-10$, we have young wind-seas. Old windseas are associated to WA values on the order of $25-30$. For WA $>30$ the wave field should be dominated by swell energy [8]. Histograms of WA, calculated using our data base for the whole region, for winter (DJF) and summer (JJA) are presented in Figure 2.

For both seasons, WA values in the range 40-60 dominate the WA distribution, above the old sea limit, indicative of swell dominance. A slight shift to lower values of WA peak distribution is seen for DJF. Winter-time distribution of WA has a smaller kurtosis as compared to the winter distribution. Lower values of WA in the range of 20-30, corresponding to old wind-sea, although a small fraction of total distribution, are present in both seasons. Therefore, albeit a minor contributor to the total wave energy, windsea near full development stage is present together with swell. Young wind-seas $(5<\mathrm{WA}<10)$ have not been observed in the distribution, which is consistent to the absence of a windsea index W near 1 in Figure 1.

As shown in Figure 3, the mean wind speed for the study region is about $7 \mathrm{~ms}^{-1}$, and approximately $90 \%$ of wind intensities are below about $8 \mathrm{~ms}^{-1}$. For low wind speed oceanic areas, results of [10] show that presence of pure wind-sea fields is almost negligible (see Figure 1 of [10]). According to [10], pure wind-seas should be present in coastal regions, enclosed seas or during extreme wind events; in open ocean swell is usually present. To evaluate the proportion of swell energy over total wave energy, [14] calculated the ratio of these two quantities by integration of swell partition versus total spectral wave energy using model results. Their global results show that swell energy is everywhere above $65 \%$, even in the extra tropics during the winter, and above $95 \%$ in the equatorial region; swell regimes were prevalent in all seasons. A mixed-seas category for our region, that still would consider a higher dominance of swell, could be associated with lower $S$ and higher $W$ indices, which are observed (Figure 1) in the ITCZ region and near the Brazilian north coast and Africa specially during the summer.

In order to compare the results obtained using the WES and WAWD methods, all our data bases of 91140 set of points $\left(H_{s}, U_{10}, C_{p}\right.$ and wave direction quadruplets) were tested for direction and wave age as indicated in Section 2.2. From 


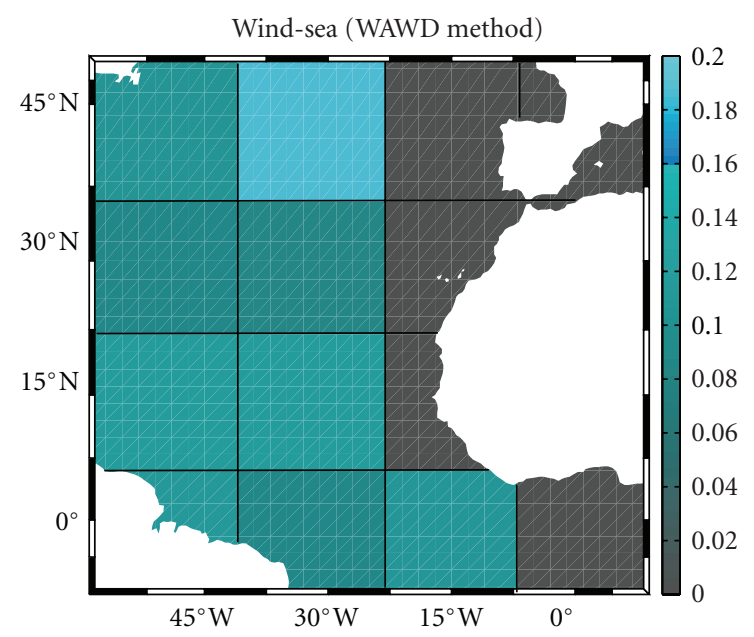

FIGURE 4: 2002-2008 average spatial distribution of the windsea points given by WAWD method (yellow points depicted in Figure 5).

all data points, 47947 satisfied the criteria of being inside the $90^{\circ}$ cone of influence, that is, the waves were more or less propagating in the wind direction. However, from this subset, only 1686 data points passed the wave age criteria (5) corresponding to about $2 \%$ of total dataset. This extremely low fraction of purely wind-sea regime in the region given by the WAWD method agrees very well with results presented in Figure 1.

Considering the reduced number of data points, it was not possible to make a plot of the spatial mean distribution of the wind-sea points given by the WAWD method with the same resolution as the wind-sea index of Figure 1. A tentative plot is, however, presented in Figure 4 in a coarse $15^{\circ} \times 15^{\circ}$ resolution and an average plot for the whole period. In each resolution cell is indicated the percentage of wind-sea points in the cell. The color bar to the right shows the distribution of the wind-sea in percentage. The eastern portion of the domain is practically void of wind-sea points. The increase in wind-sea density seen centered in $15^{\circ} \mathrm{N}$ on the ITCZ region and near the Amazon River mouth at the equator matches a similar pattern (in higher resolution) in Figure 1.

Another way of assessing the fraction of our data points that corresponds to wind-sea condition is the following: for a wind forced ocean wave systems $[25,26]$ show the existence of close correlations between the dimensionless peak frequency $\left(f_{p}{ }^{*}=f_{p} U / g\right)$ and wave energy $\left(E^{*}=\right.$ $\left.g^{2} E / U^{4}\right)$ to the dimensionless fetch $\left(x^{*}=x g / U^{2}\right)$. As shown by [16], it is possible to eliminate $x^{*}$ from these relations and derive the following equation between the wind speed $(U)$, peak period $\left(T_{P}\right)$, and significant wave height $(H)$ :

$$
\frac{U}{g T_{p}}=4.8 \times 10^{-2}\left(\frac{U^{2}}{g H}\right)^{0.66} .
$$

Figure 5 shows the scatter plot between $U / g T_{p}$ and $U^{2} / g H$ calculated from our data set ( $U$ from scatterometer, $H$ from altimeter, and $T_{p}$ from WW-III model). The solid black line represents the theoretical curve for full-developed wind sea

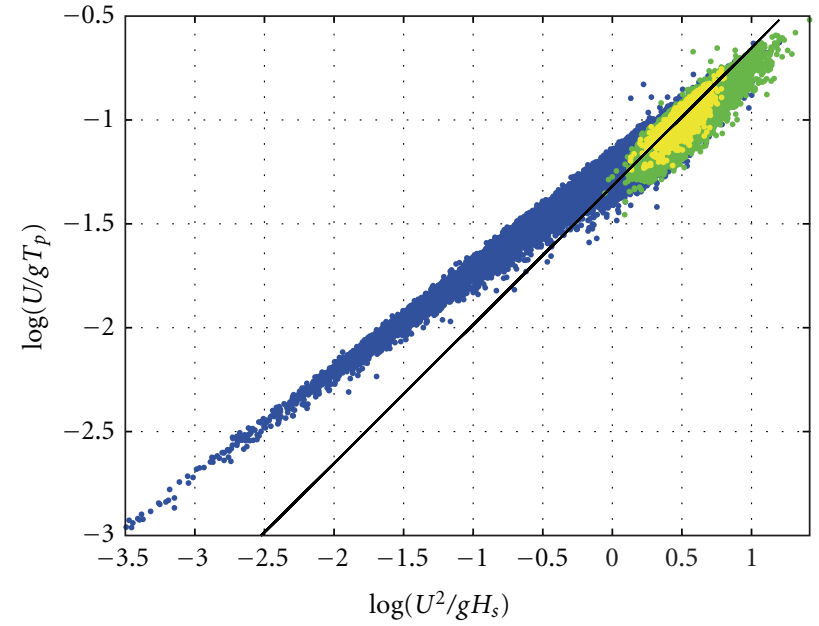

Figure 5: $\log \left(U / g T_{p}\right)$ versus $\log \left(U^{2} / g H\right)$. Solid black line represents the theoretical wind-sea relation given by $(8)[16,25]$.

given by (8). In Figure 5, the yellow region corresponds to points which passed the full WAWD test $(\sim 2 \%)$. The green points only passed the cone of influence part of WAWD method $(\sim 52 \%)$. The blue points did not pass the WAWD method. It is possible to note that the blue points are far off the theoretical fully developed wind-sea curve. These points correspond to wide range of swell fields found in the study region.

A fit between $U / g T_{p}$ and $U^{2} / g H$ just for the yellow points of Figure 5 is presented in Figure 6 (dashed line). The best fit equation to these data points is given by

$$
\frac{U}{g T_{p}}=5.2 \times 10^{-2}\left(\frac{U^{2}}{g H}\right)^{0.62} .
$$

The close similarity between the theoretical fully developed wind-sea relation given by (8) and fitted relation using only points which passed the WAWD method also confirms first that these are in fact wind-sea cases, and secondly that windsea condition represents only a very small fraction of the total wave regime in our study region.

\section{Conclusion}

In this paper we have used satellite data and wave model results to analyze the space and seasonal variability of windsea and swell wave regimes in the mid-latitude and tropical North Atlantic for the period 2002-2008. The swell/wind-sea separation was first done using an energy approach suggested by [10] that uses exclusively satellite data; significant wave height was provided by radar altimetry and surface winds derived from scatterometer sensor. The separation between swell and wind-sea is indicated by a swell index and a wind-sea growth index. The results of this methodology show very clearly the high dominance of swell over windsea throughout the study region and for both winter and summer periods. A small but clear decrease in the swell energy and an associated increase in the potential for windsea growth were observed in the tropical North Atlantic 


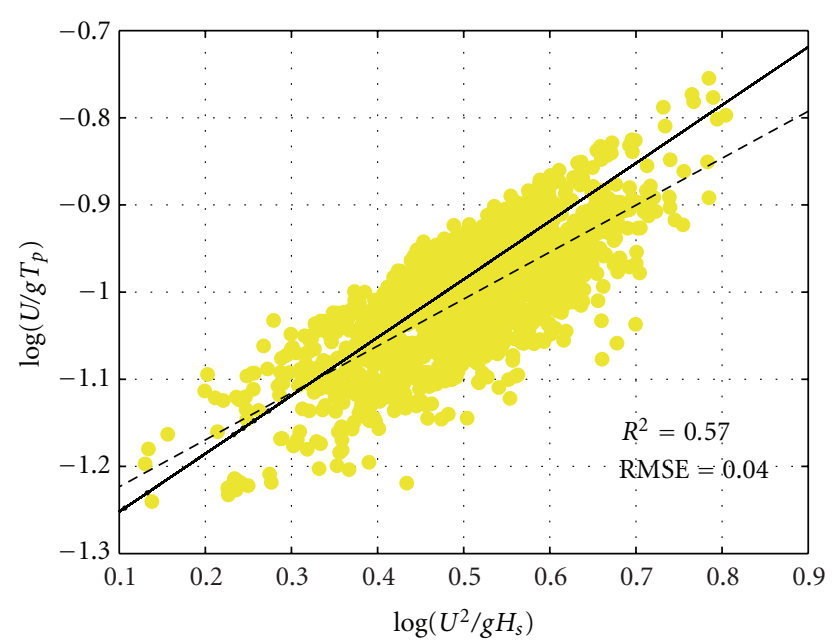

Figure 6: $\log \left(U / g T_{p}\right)$ versus $\log \left(U^{2} / g H\right)$ for data points that passed by the WAWD method (yellow points in Figure 5). Solid black line is the theoretical fully developed wind-sea line given by [16], and dashed line is the best fit line to the data (9).

NE trade winds zone. This spatial pattern of swell/wind-sea distribution is similar to those presented by different authors using distinct data sets, methods, or periods [14, 15, 23]. Also, of notice is a seasonal summertime increase in wind-sea index in the Amazon River mouth and adjacent shelf region and in Africa. This seasonal increase in wind-sea energy is probably associated with a strengthening of the alongshore $\mathrm{SE}$ and NE trade winds in these regions in the summertime. Albeit with a significantly smaller energy contribution of wind-seas as compared to swell energy, we could say that a kind of mixed seas is more evident in the region in the trade winds, with the remaining area being highly dominated by swell energy. The distribution of WA index indicates very clearly the absence of young-seas in the region.

The second method for assessing the swell/wind-sea contributions used scatterometer winds and wave spectrum peak period and wave propagation direction from wave model results. Wind-sea cases were determined from a maximum $\pm 45^{\circ}$ deviation of wind propagation direction from local winds and a maximum wave age of 1.2 (5). From a set of about $91 \mathrm{~K}$ data points, only about $2 \%$ were considered wind-sea by this method; a result in agreement to the first method. An indication of wind-sea increase in the NE trade winds region and near the Amazon shelf is present in the spatial distribution of wind-sea data points (Figure 3).

A further analysis of the swell/wind-sea regimes was done by observing the correlation between $U / g T_{p}$ and $U^{2} / g H$. As expected from the analysis using the WES and WAWD methods, the majority of data points strongly deviate from the theoretical wind-sea fully developed spectrum as given by (8). A scatter plot of data points that had passed the WAWD method (Figure 5) shows that a good fit can be adjusted with a very similar correlation law (9).

A particular difficulty in using the presented methods is associated with the very different spatial and temporal resolutions of model results and satellite data. In our study, model results were available in a grid of $1^{\circ} \times 1^{\circ}$ every 3 hours, while altimeter data is given every $7 \mathrm{~km}$ along the satellite track [16] and scatterometer winds in a spatial resolution of $25 \mathrm{~km}$. This study shows that the use of interpolated and blended satellite data and model results provided reliable estimates of theoretical and statistical indices of wave field present in the region. We argue here that the consistency observed between different approaches, using the same data set, is indicative of the reliability of results obtained.

\section{References}

[1] L. H. Houlthuijsen, Waves in Oceanic and Coastal Waters, Cambridge University Press, Cambridge, UK, 2007.

[2] C. W. Fairall, E. F. Bradley, J. E. Hare, A. A. Grachev, and J. B. Edson, "Bulk parameterization of air-sea fluxes: updates and verification for the COARE algorithm," Journal of Climate, vol. 16, no. 4, pp. 571-591, 2003.

[3] M. D. Powell, P. J. Vickery, and T. A. Reinhold, "Reduced drag coefficient for high wind speeds in tropical cyclones," Nature, vol. 422, no. 6929, pp. 279-283, 2003.

[4] I. J. Moon, I. Ginis, and T. Hara, "Impact of the reduced drag coefficient on ocean wave modeling under hurricane conditions," Monthly Weather Review, vol. 136, no. 3, pp. 1217-1223, 2008.

[5] O Saetra, J. Albretsen, and P. A. E. M. Janssen, "Sea-Statedependent momentum fluxes for ocean modeling," Journal of Physical Oceanography, vol. 37, no. 11, pp. 2714-2725, 2007.

[6] F. Collard, F. Ardhuin, and B. Chapron, "Monitoring and analysis of ocean swell fields from space: new methods for routine observations," Journal of Geophysical Research C, vol. 114, no. 7, Article ID C07023, 2009.

[7] W. Pierson and L. Moskowitz, "A proposed spectral form for fully developed wind seas based on the similarity theory of s.a. Kitaigordskii," Journal of Geophysical Research, vol. 69, pp. 5181-5190, 1964.

[8] G. J. Komen, L. Cavaleri, M. Donelan, K. Hasselmann, S. Hasselmann, and P. Janssen, Dynamics and Modelling of Ocean Waves, Cambridge University Press, Cambridge, UK, 1994.

[9] P. A. Hwang, H. García-Nava, and F. J. Ocampo-Torres, "Dimensionally consistent similarity relation of ocean surface friction coefficient in mixed seas," Journal of Physical Oceanography, vol. 41, pp. 1227-1238, 2011.

[10] G. Chen, B. Chapron, R. Ezaraty, and D. Vandemark, "A global view of swell and wind sea climate in the ocean by satellite altimeter and scatterometer," Journal of Atmospheric and Oceanic Technology, vol. 19, pp. 1849-1859, 2002.

[11] F. Ardhuin, B. Chapron, and F. Collard, "Observation of swell dissipation across oceans," Geophysical Research Letters, vol. 36, no. 6, Article ID L06607, 2009.

[12] M. A. Donelan, W. H. Hui, and J. Hamilton, "Directional spectra of wind-generated waves," Philosophical Transactions of the Royal Society A, vol. 315, no. 1534, 1985.

[13] G. Dodet, X. Bertin, and R. Taborda, "Wave climate variability in the North-East Atlantic Ocean over the last six decades," Ocean Modelling, vol. 31, no. 3-4, pp. 120-131, 2010.

[14] A. Semedo, K. Suselj, A. Rutgersson, and A. Sterl, "A global view on the wind sea and swell climate and variability from ERA-40," Journal of Climate, vol. 24, pp. 1461-1479, 2011.

[15] K. E. Hanley, S. E. Belcher, and P. P. Sullivan, "A Global climatology of wind-wave interaction," Journal of Physical Oceanography, vol. 40, no. 6, pp. 1263-1282, 2010. 
[16] P. A. Hwang, W. J. Teague, G. A. Jacobs, and D. W. Wang, "A statistical comparison of wind speed, wave height, and wave period from satellite altimeters and ocean buoys in the Gulf of Mexico region," Journal of Geophysical Research, vol. 103, pp. 451-468, 1998.

[17] R. E. Glazman and S. H. Pilorz, "Effects of sea maturity on satellite altimeter measurements," Journal of Geophysical Research, vol. 95, no. 3, pp. 2857-2870, 1990.

[18] NASA Quick Scatterometer, "QuikSCAT science data product, user's manual, overview \& geophysical data products," 2000, Version 2.0-Draft, Jet Propulsion Laboratory, California Institute of Technology, Doc. D-18053.

[19] H. Tolman, "User manual and system documentation of WaveWatch 3 version 3.14," Tech. Rep. NOAA/NWS/NCEP/ MMAB, 2009.

[20] D. P. Dee, "collaborators The ERA-Interim reanalysis: configuration and performance of the data assimilation system," Quarterly Journal of the Royal Meteorological Society, vol. 137, pp. 553-597, 2011.

[21] S. Hasselmann, "The WAM model: a third generation ocean wave prediction model," Journal of Physical Oceanography, vol. 18, pp. $1775-1810,1988$.

[22] C. Pianca, P. L. F. Mazzini, and E. Siegle, "Brazilian offshore wave climate based on NWW3 reanalysis," Brazilian Journal of Oceanography, vol. 58, no. 1, pp. 53-70, 2010.

[23] I. R. Young, "Seasonal variability of the global ocean wind and wave climate," International Journal of Climatology, vol. 19, no. 9, pp. 931-950, 1999.

[24] Edson J. et al., "The coupled boundary layers and air-sea transfer experiment in low winds," Bulletin of the American Meteorological Society, vol. 88, pp. 341-356, 2007.

[25] Hasselmann K. and al et, "Measurements of wind-wave growth and swell decay during the joint north sea wave project(JONSWAP)," Tech. Rep. Ergänzungsheft zur Deutschen Hydrographischen Zeitschrift, 1973.

[26] Hasselmann K., B. Ross D., Miller P., and Sell W., "A parametric wave prediction model," Journal of Physical Oceanography, vol. 6, pp. 200-228, 1976. 

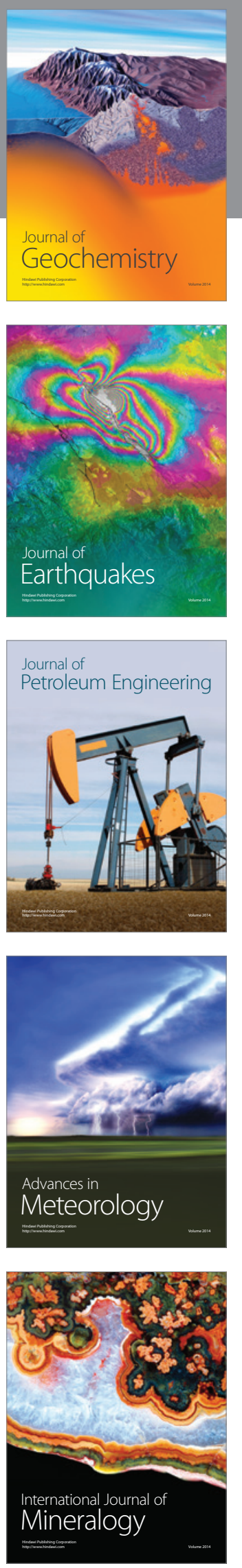
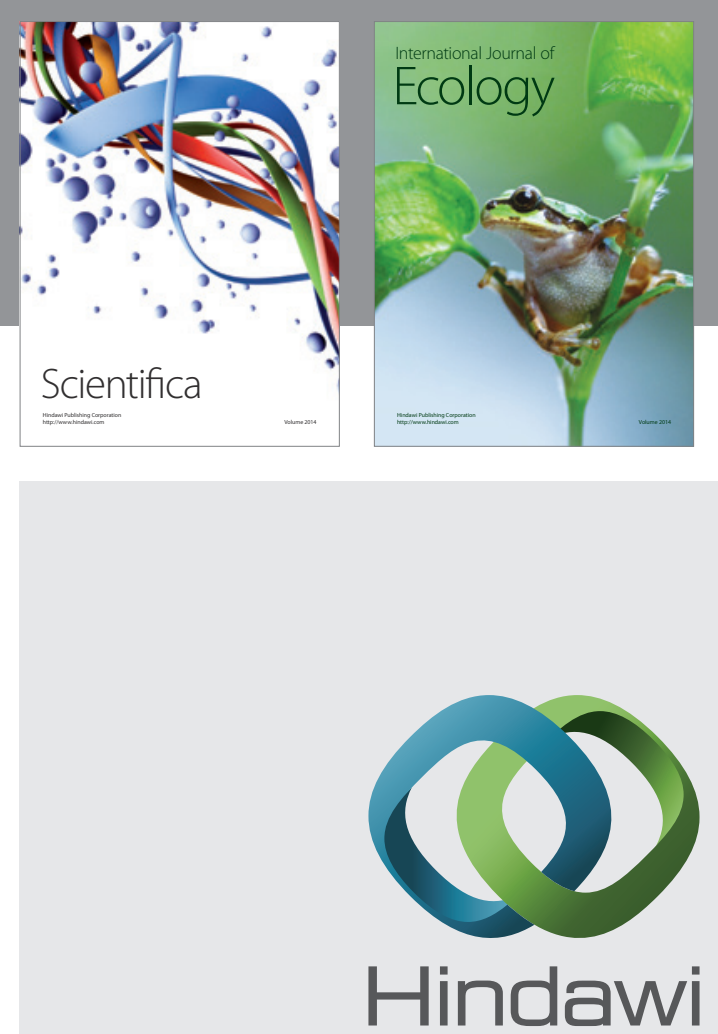

Submit your manuscripts at http://www.hindawi.com
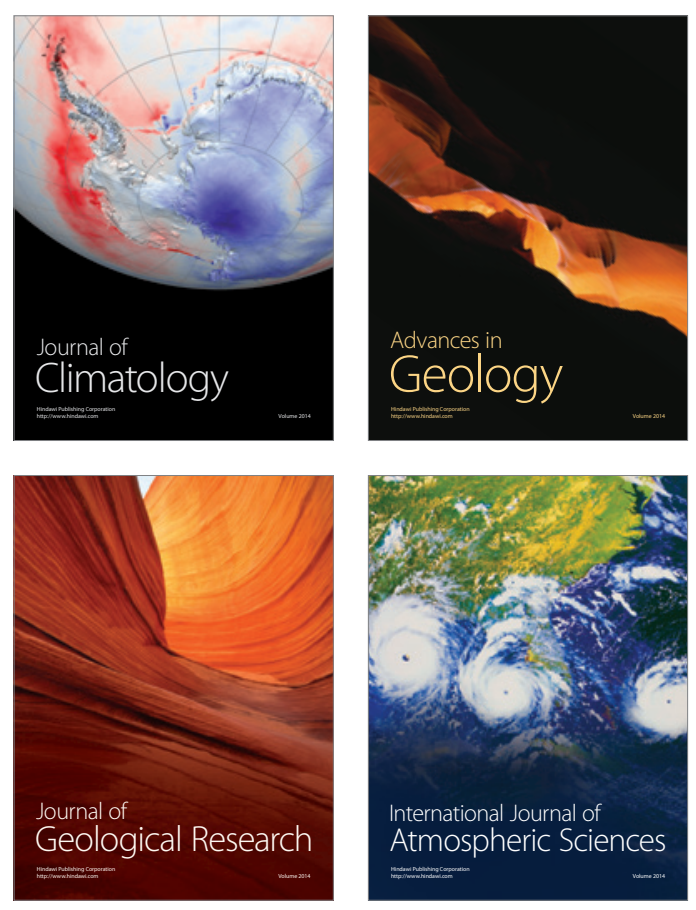
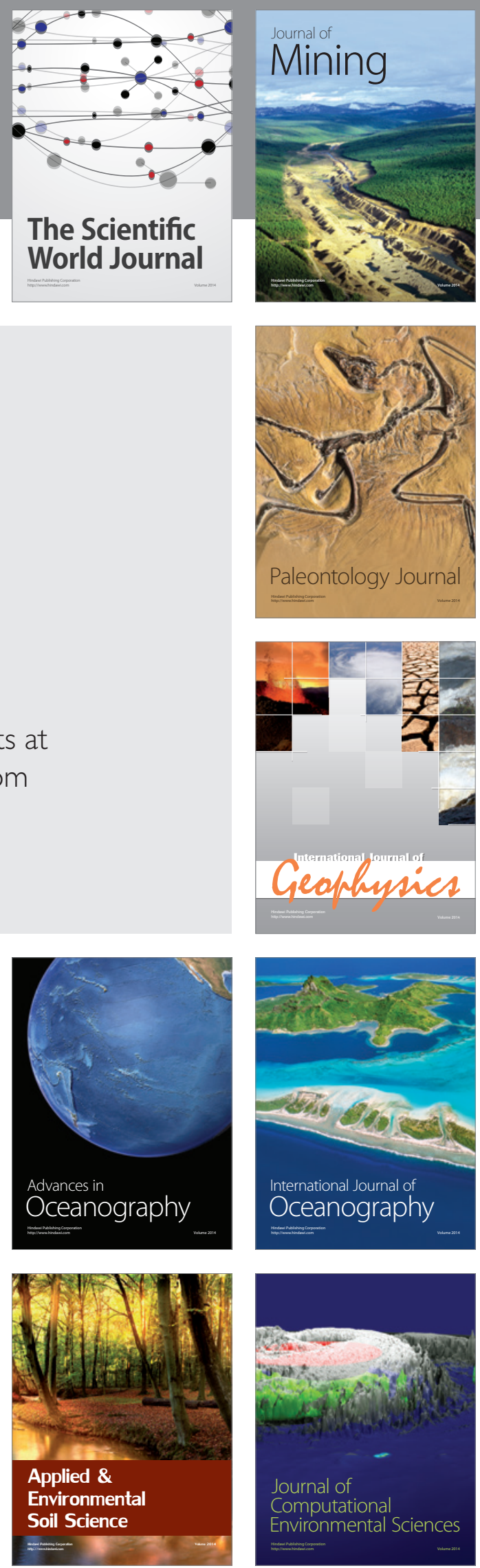